\title{
A Simple Method for Determining Antitubulinic Activities of Ansamitocins and Related Compounds Using a Cilia Regeneration System with Deciliated Tetrahymena
}

\author{
Seiichi Tanida, Toru Hasegawa and Eiji Higashide \\ Microbiological Research Laboratories, Central Research Division, \\ Takeda Chemical Industries, Ltd., \\ 17-85, Jusohonmachi 2-chome, Yodogawa-ku, Osaka 532. Japan
}

Received January 7, 1980

\begin{abstract}
Cilia regeneration with deciliated Tetrahymena pyriformis $\mathrm{W}$ was tested to determine the antitubulinic activities of ansamitocins and related compounds in a microbial system. Various factors interfered with the regeneration process, i.e. excess shearing force in deciliation procedure, high temperature $\left(32^{\circ} \mathrm{C}\right.$ or above), high or low $\mathrm{pH}(\mathrm{pH} 9$ or 5$)$, and exogenous divalent cations, such as $\mathrm{Zn}^{2+}, \mathrm{Mn}^{2+}, \mathrm{Cu}^{2+}$ and $\mathrm{Co}^{2+}$. Under suitable conditions, cilia regeneration was completed in about $60 \mathrm{~min}$ of incubation, and a number of newly formed cilia were observed around the cell surface. When ansamitocins were added to the recovery solution, cilia regeneration was completely suppressed without alterations in cell shape or the surface structure of deciliated Tetrahymena. In this assay system, the inhibitory activity of ansamitocins was slightly stronger than that of maytansine.
\end{abstract}

The cilia and flagella in eukaryotic microorganisms contain highly organized microtubule systems." The formation process of these organelles depends on the assembly of tubulin to ciliary or flagellar microtubules, and is affected by antimitotic agents. ${ }^{2 \sim 6)}$ Rosenbaum and $\mathrm{Carlson}^{2)}$ developed the model system for cilia formation of Tetrahymena using deciliated cells in which regeneration of cilia was determined as recovery of motility from nonmotile cells. We have found that ansamitocins, maytansinoid antitumor antibiotics, ${ }^{7 \sim 9)}$ have strong activity to inhibit cilia regeneration of Tetrahymena. Part of this finding has been reported and we suggested the possibility that the regeneration system is a useful tool for determining the antitubulinic properties of ansamitocins and related compounds. ${ }^{6)}$

This paper deals with the factors affecting cilia regeneration of deciliated Tetrahymena and the inhibitory effect of ansamitocins and maytansine ${ }^{10)}$ on regeneration.

\section{MATERIALS AND METHODS}

Media and culture. T. pyriformis $\mathrm{W}$ was used in all experiments. The growth medium (PPYG) contained proteose-peptone (Difco), $2 \%$; yeast extract (Difco), 0.1\%; glucose, $0.2 \%$. The cells were grown for 2 days at $28^{\circ} \mathrm{C}$ without shaking. The cell density at this time was about $5 \times 10^{5} / \mathrm{ml}$. The organism was maintained in PPYG at room temperature and transplanted to fresh PPYG at two-week intervals.

Assay for cilia regeneration. A $0.5 \mathrm{ml}$ portion of the stock culture was introduced into $20 \mathrm{ml}$ PPYG in a $250 \mathrm{ml}$ Erlenmyer flask and incubated for 2 days at $28^{\circ} \mathrm{C}$. The cells were harvested at room temperature by centrifugation at $200 \times g$ for $3 \mathrm{~min}$. After removal of the supernatant by aspiration, the pellet was resuspended in $5 \mathrm{ml}$ cold PPYG. Deciliated cells were obtained by the method of Rosenbaum and Carlson ${ }^{2)}$ with some modifications. A $2 \mathrm{ml}$ portion of the suspension was added to $4 \mathrm{ml}$ cold EDTA-acetate buffer (10 mM EDTA.2Na; $50 \mathrm{~mm}$ sodium acetate, $\mathrm{pH} 6.0$ ) in a $50 \mathrm{ml}$ centrifuge tube with a screw cap. After addition of $2 \mathrm{ml}$ of cold distilled water, followed by the addition of $0.2 \mathrm{ml}$ of $0.2 \mathrm{M} \mathrm{CaCl}_{2}$, the tube was inverted five times. If necessary, the suspension was subjected to shearing with a $5 \mathrm{ml}$ glass syringe with a needle. To $1 \mathrm{ml}$ of a recovery solution (mainly $0.02 \mathrm{M}$ potassium phosphate buffer, $\mathrm{pH} 7.0$ ), $0.05 \mathrm{ml}$ of the deciliated cell suspension was added and 

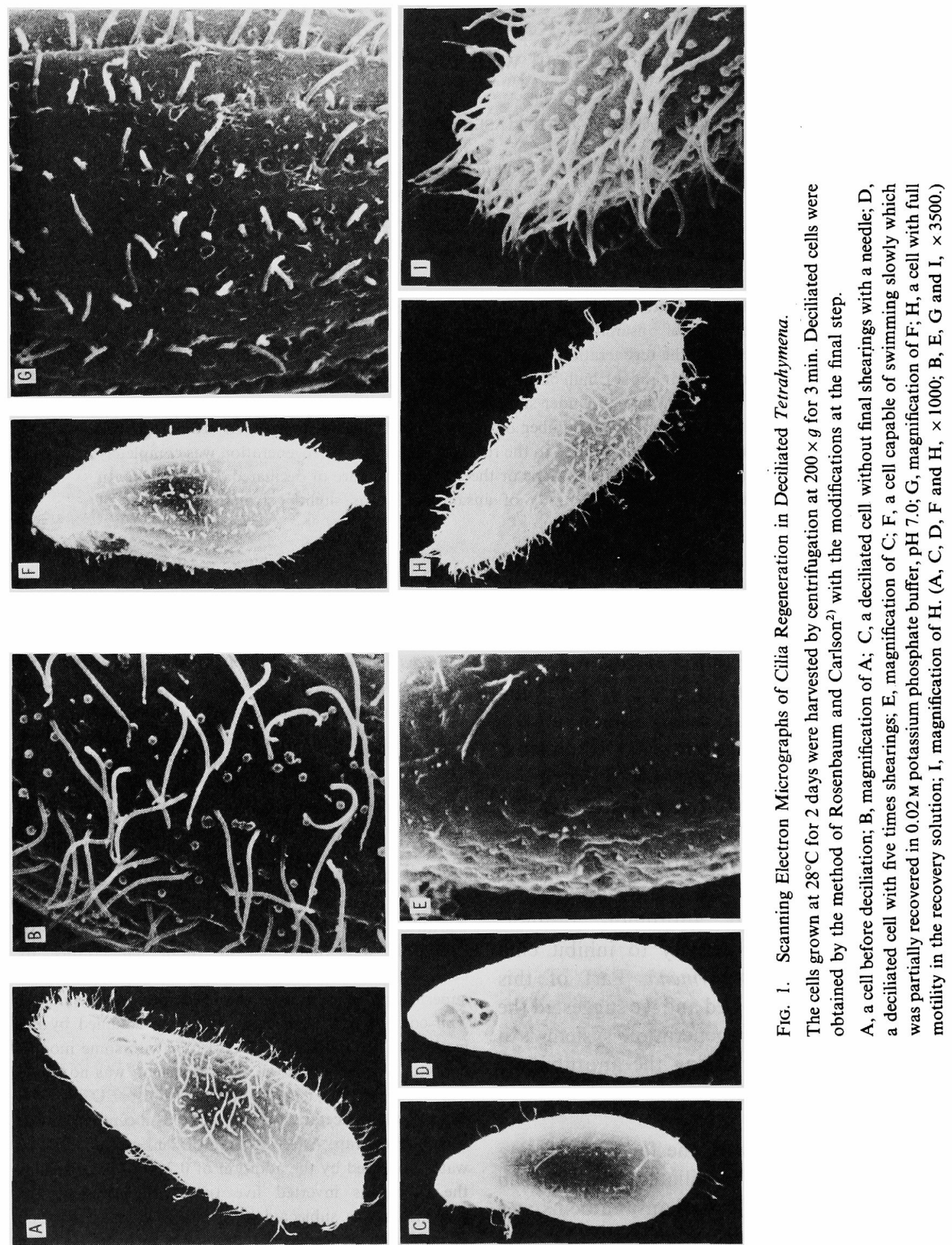
incubated at $28^{\circ} \mathrm{C}$. Ansamitocins and maytansine were added to the recovery solution prior to the addition of the cell suspension. The regeneration of cilia was assayed by observing the recovery of motility in deciliated cells with a microscope ( $\times 40$ magnification).

Scanning electron microscopy. Tetrahymena cells fixed with $0.1 \%$ glutaraldehyde were dehydrated through ethyl alcohol series. For scanning electron microscopy the cells were critical-point dryed, coated with gold and viewed on a MSM4C-101 scanning electron microscope.

Chemicals. Ansamitocin P-3 and P-4, purified from a culture broth of Nocardia sp. C-15003 (N-1), ${ }^{8,9)}$ were dissolved in methanol to a final concentration of $1,000 \mu \mathrm{g} / \mathrm{ml}$ and stored at $-20^{\circ} \mathrm{C}$. Under these conditions the biological activity of ansamitocins is stable for more than one month. Maytansine used in this experiment was prepared in our research division.

\section{RESULTS AND DISCUSSION}

Influence of shearing force on deciliation of Tetrahymena

The condition of deciliation is traumatic to the maintenance of viability in Tetrahymena. In order to obtain deciliated cells with minor loss of viability, deciliation was carried out accord-

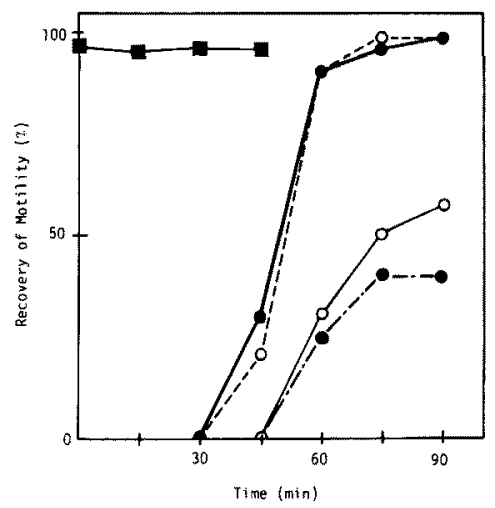

Fig. 2. Recovery of Motility of Deciliated Tetrahymena.

Deciliated cells were prepared as in Fig. 1. To $1 \mathrm{ml}$ of $0.02 \mathrm{M}$ potassium phosphate buffer, $\mathrm{pH} 7.0,0.05 \mathrm{ml}$ of deciliated cell suspension was added and incubated at $28^{\circ} \mathrm{C}$ without shaking. Recovery of motility was assayed by scoring of motile cells with a phase contrast microscope.

- - inverted the tube; --- inverted the tube followed by shearing five times with a needle; $\mathrm{O}-\mathrm{O}$, inverted the tube followed by shearing once; $\bigcirc--O$, only shearing five times; $-\square$, no physical force added. ing to the procedure of Rosenbaum and Carlson $^{2)}$ with the modification of shearing at the final step of this treatment. Scanning electron microscopic observation shows that all of the deciliated cells (Fig. 1C, D, E) lost most of their cilia and ceased swimming, and that the cells were also damaged by this treatment resulting in a rough surface (Fig. $1 E)$ as compared with that of the normal cell (Fig. 1A, B). The deciliated cells prepared by inverting the tube with the cell suspension followed by shearing five times with a needle lost some of oral and all of somatic cilia (Fig. 1D), whereas the cells without the final shearings still had oral and a few somatic cilia (Fig. 1C). Figure 2 shows the kinetics of recovery of motility of the deciliated cells in $0.02 \mathrm{M}$ potassium phosphate buffer, $\mathrm{pH} 7.0$ as the recovery solution. After $60 \mathrm{~min}$ of incubation, more than $90 \%$ of the deciliated cells without final shearings were fully motile. As shown in Fig. $1 \mathrm{H}$ and $\mathrm{I}$, cells recovering their motility had numerous newly formed cilia on their surface. In the early stage of cilia regeneration, many of the slow swimming cells had many immature short cilia (Fig. 1F, G). On the other hand, only half of the deciliated

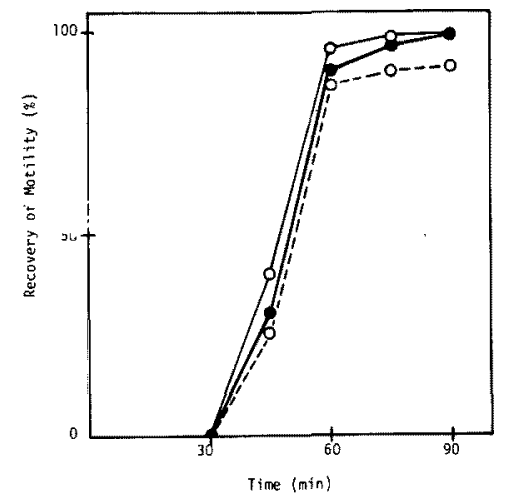

FIG. 3. Effect of Recovery Solutions on Cilia Regeneration in Deciliated Tetrahymena.

Deciliated cells were prepared by only inverting the tube for detachment of cilia. Procedures are the same as in Fig. 2.

- - in $0.02 \mathrm{M}$ potassium phosphate buffer, $\mathrm{pH} 7.0$; $\mathrm{O}-\mathrm{O}$, in $0.05 \mathrm{M}$ Tris- $\mathrm{HCl}$ buffer, $\mathrm{pH} 7.5 ; \mathrm{O}-\mathrm{O}$, in PPYG. 


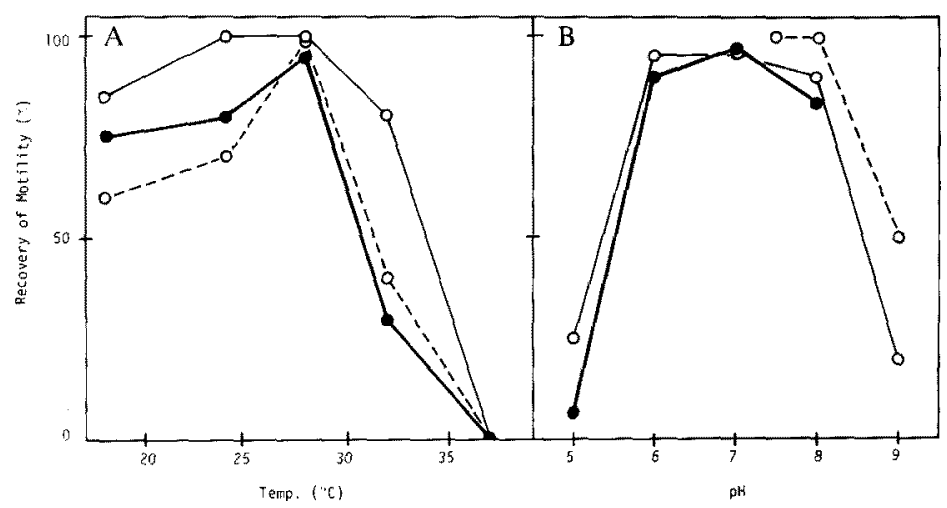

FIG. 4. Effect of Temperature and $\mathrm{pH}$ on Cilia Regeneration in Tetrahymena.

Conditions are the same as in Fig. 2 except incubation temperature and pH of the recovery solution. After $90 \mathrm{~min}$ of incubation, motile cells were scored.

A, recovery of motility in varying temperature; $\mathrm{B}$, recovery of motility in varying $\mathrm{pH}$, with phosphate buffer (O), Tris- $\mathrm{HCl}$ buffer $(\mathrm{O}-\mathrm{O})$ or PPYG $(\mathrm{O}-\mathrm{O})$.

cells with once or five times shearings recovered their motility because of the loss of viability of many cells during this treatment. When a cell suspension after addition of $\mathrm{CaCl}_{2}$ was immediately subjected to shearing five times, the recovery pattern of these cells was similar to that of the cells deciliated without final shearing (Fig. 2). Although shearing with a needle at the final step in this procedure was not necessary to obtain deciliated cells, physical force was essential for the detachment of cilia. Most of the cells after addition of $\mathrm{CaCl}_{2}$ were capable of swimming in the recovery solution unless the tube was inverted or shearing with a needle was followed (Fig. 2). From these results, deciliated Tetrahymena was prepared without shearing at the final step of this procedure.

Effect of environmental factors on cilia regeneration in Tetrahymena

In order to determine the antitubulinic activity of ansamitocins in culture broths on the cilia regeneration system in deciliated Tetrahymena, effect of various environmental factors on the regeneration process were examined. Figure 3 shows the recovery kinetics of deciliated cells in various recovery solutions. No significant difference was observed among the recovery patterns. The incubation temperature and $\mathrm{pH}$ of recovery solutions affected the cilia regeneration. After $90 \mathrm{~min}$ of incubation, normal recovery of motility was obtained in the variation between 24 to $28^{\circ} \mathrm{C}$, and between pH 6 to 8 (Fig. $4 \mathrm{~A}, \mathrm{~B}$ ). At $32^{\circ} \mathrm{C}$ or above, recovery of motility was reduced. Similarly, reduction in the recovery of motility was observed at $\mathrm{pH} 5$ or 9 . The effect of temperature and $\mathrm{pH}$ on cilia regeneration was correlated with that on growth of Tetrahymena, ${ }^{111}$ and therefore, the interfering effect was due to nonspecific actions to the organism.

Ansamitocins are produced by an actinomycete, Nocardia sp. No. C-15003 (N-1), ${ }^{7,8)}$ in liquid media. In order to determine the amount of ansamitocins in culture broths of the Nocardia, effect of compounds commonly used as components of the culture media for fermentative production were tested with $0.05 \mathrm{~m}$ Tris- $\mathrm{HCl}$ buffer, $\mathrm{pH} 7.5$ as the recovery solution. As shown in Fig. 5, raising the concentration of $\mathrm{KCl}, \mathrm{NaCl}$ or potassium phosphate buffer caused marked reduction of cilia regeneration. The suppression by potassium phosphate buffer at $0.1 \mathrm{M}$ or above may be mainly due to the function of the $\mathrm{K}^{+}$ion and not of the phosphate ion. Some of the divalent cations also affected regeneration. As shown in Fig. 6, $\mathrm{ZnCl}_{2}$ at $0.5 \mathrm{~mm}, \mathrm{MnCl}_{2}$ at 


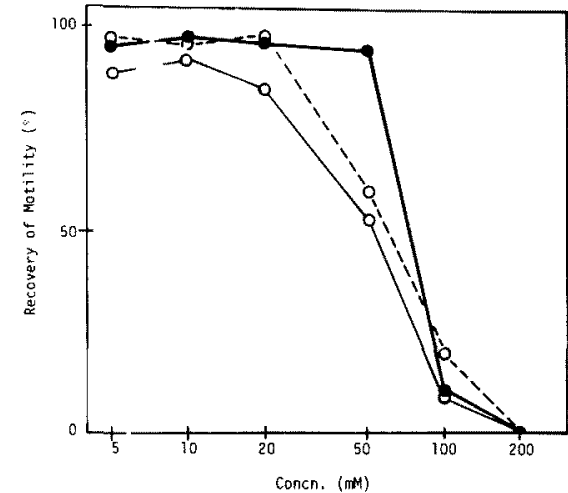

FIG. 5. Effect of Monovalent Cations on Cilia Regeneration in Tetrahymena.

Conditions are the same as in Fig. 2 except $0.05 \mathrm{M}$ Tris$\mathrm{HCl}$ buffer, $\mathrm{pH} 7.5$ was used as the recovery solution.

- - potassium phosphate; $\mathrm{O}-\mathrm{O}, \mathrm{KCl} ; \mathrm{O}-\mathrm{O}$, $\mathrm{NaCl}$.

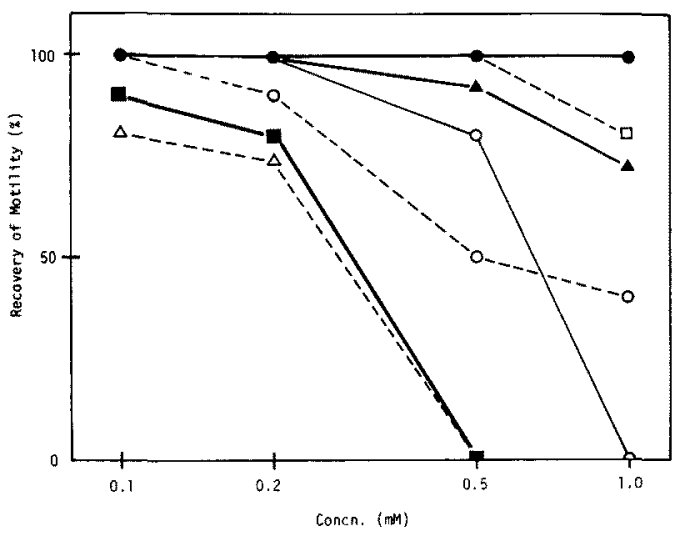

FIG. 6. Effect of Divalent Cations on Cilia Regeneration in Tetrahymena.

Conditions are the same as in Fig. 5.

- $\mathrm{CaCl}_{2}, \mathrm{BaCl}_{2}$ or $\mathrm{MgSO}_{4} ; \square--\square, \mathrm{FeSO}_{4}$;

$\boldsymbol{\Delta}-\boldsymbol{\Delta}, \quad \mathrm{NiCl}_{2} ; \quad \mathrm{O}-\mathrm{O}, \quad \mathrm{CoCl}_{2} ; \quad \mathrm{O}-\mathrm{O}, \quad \mathrm{CuSO}_{4}$;

$\mathbf{\square}, \mathrm{ZnCl}_{2} ; \triangle--\triangle, \mathrm{MnCl}_{2}$.

$0.5 \mathrm{mM}$ or $\mathrm{CuSO}_{4}$ at $1 \mathrm{~mm}$ completely suppressed cilia regeneration, and $\mathrm{CoCl}_{2}$ at 0.5 to $1 \mathrm{~mm}$ showed partial inhibition. Although $\mathrm{CaCl}_{2}$ is known to cause interference with the polymerization of tubulin to microtubules in vitro, ${ }^{1)}$ cilia regeneration was not affected by $\mathrm{CaCl}_{2}$ at levels up to $1 \mathrm{~mm}$. On the basis of these results, determination of the amount of ansamitocins in culture broths of Nocardia sp.
No. C-15003 (N-1) was examined. Since cations in the fermentation media ${ }^{8 /}$ for production of ansamitocins are less than levels that affect cilia regeneration, the amount of the antibiotics in the culture was able to be determined by the assay system with $0.05 \mathrm{M}$ Tris- $\mathrm{HCl}$ buffer, $\mathrm{pH} 7.5$ containing up to $50 \%$ $(\mathrm{v} / \mathrm{v})$ of the supernatant of the culture broth which was prepared by centrifugation at $3000 \times g$ for $10 \mathrm{~min}$ at room temperature. The inhibitory activity depends on the amount of ansamitocins because the antibiotics are only products with antitubulinic properties of the Nocardia. As compared with the in vitro polymerization system for tubulin to microtubules, ${ }^{1)}$ the cilia regeneration system was relatively tolerant to various environmental factors. Therefore the regeneration system is suitable in the determination of the antitubulinic properties of fermentation products.

Effect of ansamitocins and maytansine on cilia regeneration in Tetrahymena

Ansamitocins at low concentrations prevent cilia regeneration in deciliated Tetrahymena. ${ }^{6}$ When deciliated cells were exposed to ansamitocin P-3 at $1 \mu \mathrm{g} / \mathrm{ml}$, no cilia regeneration occurred and the cell shape remained unaffected (Fig. 7). But the surface structure of the cells recovered from the damage caused by the deciliation treatment. In this experiment, no significant difference was observed between ansamitocins P-3 and P-4. This indicates that ansamitocins have specific actions against cilia formation process in this system, probably due to interference with the assembly of tubulin to ciliary microtubules. On the basis of structural similarity, effect of maytansine ${ }^{10)}$ originated from plants with antitumor and antimitotic properties, ${ }^{12 \sim 17)}$ on cilia regeneration of Tetrahymena was tested. As shown in Fig. 8. maytansine interfered with cilia regeneration of deciliated Tetrahymena at low concentrations. The inhibitory activity was slightly weaker than that of ansamitocins. The action of maytansine, like ansamitocins, may be based on its antitubulinic properties. ${ }^{12-17)}$

From the present results, cilia regeneration 

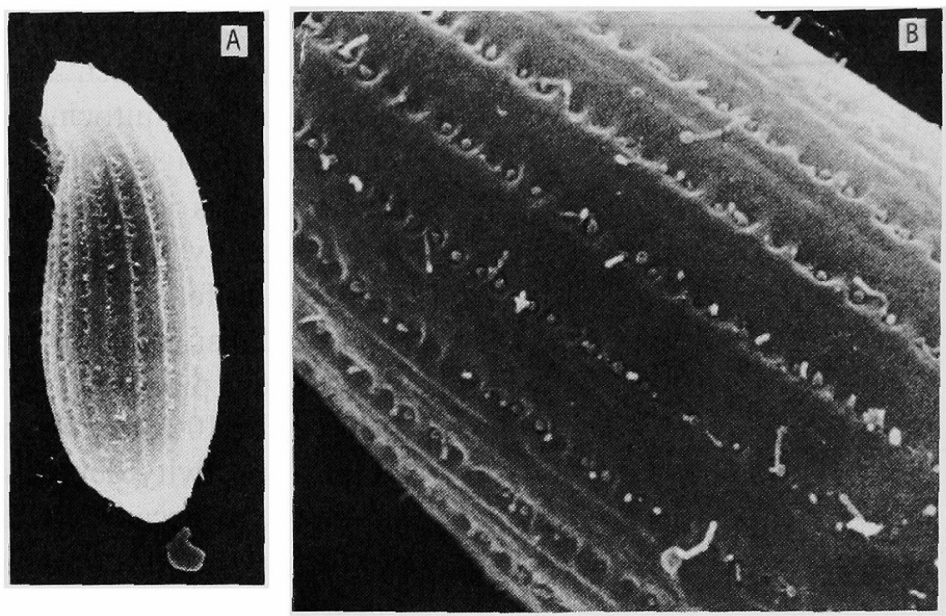

FIG. 7. Scanning Electron Micrographs of Inhibition of Cilia Regeneration in Tetrahymena by Ansamitocin P-3.

Ansamitocin P-3 was added at $1 \mu \mathrm{g} / \mathrm{ml}$ to $0.02 \mathrm{M}$ potassium phosphate buffer before inoculation of the deciliated cell suspension. After $90 \mathrm{~min}$ of incubation, the cells were fixed with glutaraldehyde and were observed by a scanning electron microscope.

A, ansamitocin P-3 added; B, magnification of A. (A, $\times 1000 ; \mathrm{B}, \times 3500$.)

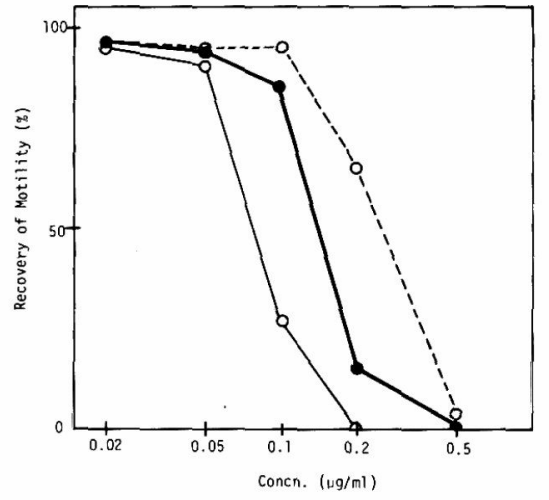

Fig. 8. Effect of Ansamitocins and Maytansine on Cilia Regeneration in Tetrahymena.

Ansamitocin P-3, P-4 or maytansine, in varying concentrations, was added to the recovery solution before inoculation of the deciliated cell suspension. After $90 \mathrm{~min}$ of incubation, motile cells were scored.

- ansamitocin P-3; O-O, ansamitocin P-4; O-- 0 , maytansine.

sytem using deciliated Tetrahymena is thought to be a simple and rapid tool for determining the activity of ansamitocins and related compounds, and other antimitotic agents in fermentation broths against microtubule systems in eukaryotic cells.
Acknowledgments. We thank Dr. E. Ohmura and Dr. M. Yoneda for their encouragement, and Dr. N. Hashimoto for his fruitful discussion. We also thank Mrs. $\mathrm{K}$. Jinno for her technical assistance.

\section{REFERENCES}

1) R. E. Stephens and K. T. Edds, Physiological Reviews, 56, 709 (1976).

2) J. L. Rosenbaum and K. Carlson, J. Cell Biol., 40, 415 (1969).

3) J. L. Rosenbaum, J. E. Moulder and D. L. Ringo, ibid., 41, 600 (1969).

4) D. L. Brown and G. B. Bouck, ibid., 56, 360 (1973).

5) J. Rannestad, ibid., 63, 1009 (1974).

6) S. Tanida, E. Higashide and M. Yoneda, Antimicrab. Ag. Chemother., 16, 101 (1979).

7) E. Higashide, M. Asai, K. Ootsu, S. Tanida, Y. Kozai, T. Hasegawa, T. Kishi, Y. Sugino and M. Yoneda, Nature, 270, 721 (1977).

8) S. Tanida, T. Hasegawa, K. Hatano, E. Higashide and M. Yoneda, J. Antibiotics, 33, 192 (1980).

9) M. Asai, E. Mizuta, M. Isawa, K. Haibara and T. Kishi, Tetrahedron, 35, 1079 (1978).

10) S. M. Kupchan, Y. Komoda, W. A. Court, G. J. Thomas, R. M. Smith, A. Karin, C. J. Gilmore, R. C. Haltiwanger and R. F. Bryan, J. Am. Chem. Soc., 94, 1354 (1972)

11) L. P. Everhart, Jr., Methods in Cell Physiol., 5, 219 (1972). 
12) S. Remillard, L. I. Rebhun, G. A. Howie and S. M. Kupchan, Science, 189, 1002 (1975).

13) M. K. Wolpert-DeFilippes, V. H. Bono, Jr., R. L. Dion and D. G. Johns, Biochem. Pharmacol., 24, 1735 (1975).

14) F. Mandelbaum-Shavit, M. K. Wolpert-DeFilippes and D. G. Johns, Biochem. Biophys. Res. Comm., 72,
47 (1976).

15) B. Bhattacharyya and J, Wolf, FEBS Lett., 75, 159 (1977).

16) R. K. Johnson, T. Inouye and M. K. WolpertDeFilippes, Biochem. Pharmacol., 27, 1973 (1978).

17) P. N. Ras, E. J. Freireich, M. L. Smith and T. L. Loo, Cancer Res., 39, 3152 (1979). 